\title{
Long-term Observations and Own Concepts in Cleft Lip and Palate Repair
}

\author{
Kazimierz Kobus $^{1 *}$, Katarzyna Kobus-Zaleśna ${ }^{2}$ and Mariusz Wysocki ${ }^{3}$ \\ ${ }^{1}$ Hospital and Clinic of Plastic Surgery, Polanica-Zdrój, Poland \\ ${ }^{2}$ Department of Maxillofacial Orthopaedics and Orthodontics, Wrocław Medical University, Poland \\ ${ }^{3}$ Department of Plastic Surgery, Specialist Medical Centre, Polanica-Zdrój, Poland
}

Received: December 05, 2014; Accepted: March 06, 2015; Published: April 08, 2015

*Corresponding author: Kazimierz Kobus, Ul. Boczna 4A, 57-320 Polanica-Zdrój, Poland, Tel: + 004-874-868-1434; E-mail: k.kobus@chir-plast.pl

\begin{abstract}
On the basis of thirty five year observations (K.K.) and clinical material comprising over 5500 primary clefts, compilation of acknowledged and own methods aimed at comprehensive cleft lip and palate repair is presented and brought for discussion.

Long-term observations appear to confirm, that although not an optimum one, the rather conservative treatment with the use of sparing methods enables achievement of satisfactory appearance, intelligible speech and acceptable occlusion with only limited impairment of midface development.

According to our observations, not always optimal results should be mostly attributed to underestimated tissue deficiency. Since so called "borrowing" of vomer or buccal tissues is far from ideal, the aim of this study is also to stress the rationale and potential of tissue augmentation. The palate repair with use of osmotic expanders is mentioned as a preliminary report only, but it shoud be regarded as a new and promising method of cleft repair.
\end{abstract}

\section{Introduction}

Specificity of cleft repair consists in a variety of malformations, early repair and multidisciplinary treatment, the effectiveness of which can be evaluated after completion of growth process.

The flood of publications and multiplicity of so-called treatment protocols are an essential problem. Valuable reports mix with pseudo-scientific data, so one can find confirmation or denial of almost every thesis, method or idea. So far, over 200 combinations of timing, operative methods, and sequence of treatment have been described, with a bleak prospect for adoption of common policy and agreement.

Among the most essential and controversial approaches, there is timing and rationale for early and even simultaneous cleft lip and palate repair, as well as the use of so-called sparing operations [1-5] aimed at replacement of harmfull mucoperiosteal flap elevation for palate repair.

Despite the risk of midface unerdevelopment, there is a tendency to early operations, which meets understandable interest of parents wishing to see their babies cured almost immediately after birth. Arguments are of a complex nature
- starting from enhancement of feeding and early speech production to alleviation of parental stress resulting from abnormal child's appearance.

So far, despite some clever achievements [6-7], evidence in favor of modern approach is rather limited and, to some degree, it is based on criticism of old methods. Advocates of early and radical procedures argue that inhibitory effects of surgical trauma and scars are noted after many and more operations, including conservative methods and so-called sparing procedures [8]. What is more, some of them believe that even if, as a result of earlier treatment, the percentage of patients with midface hypoplasia is greater, there is still possibility for orthognathic operations. In other words, in order to gain interim success, they are inclined to shift the responsibility and burden of treatment as far as possible.

The value of treatment ought to be verified by outcomes following growth completion. Unfortunately, evaluations based on large cohorts and long-term observations are rather sparse indeed, and due to the lack of precise measurements they are seldom quoted. Hence, continuous disputes and controversies are rarely based on unquestionable scientific proofs, and it definitely is not Evidence Based Medicine (EBM).

Orthodontic measurements might serve as an exception [9]. However, numerous factors affecting treatment results preclude general evaluation of applied procedures.

Speech assessment is very difficult because apart from nasality and some qualitative analysis, its evaluation is highly subjective. Moreover, speech evaluation in various language groups escapes comparison since for example light nasality in French is perceived as normal, whereas in Polish, or Czech, due to accumulation of consonants, the language requirements are higher.

Similar observations refer to appearance. Admittedly, any aberration might be calculated on the computer, yet measurement specification of subsequent face elements proves almost nothing. Neither the calculations sum up in a simple way, nor do they display face appearance as a whole. Moreover, even the computed-assisted measurements, photogrammetry or spiral tomography unable the assessment of naso-labial complex 
during speaking, eating or smiling.

Taking the above into consideration, instead of partial statistical studies, the best, although not evidence based solution seems to be presentation of optimum outcomes of cleft repair with the use of specific methods. Assumption that the best examples selected from the great number of cases will not totally endorse the value of applied treatment and average results is evidently legitimate, yet -apart from orthodontic measurementsthe accurate data and figures are often doubtful too. What is more, some unfavourably repaired patients circulate for better treatment between cleft centers, escaping any statistics.

Taking this above into consideration, despite incomplete calculations, presentation of applied for many years methods potential seems to be reasonable and justified. This concept is neither ideal nor completely scientific, but indication of optimum might serve as a reference point in comparison of various treatment methods efficacy.

An evaluation of outcomes embraces appearance, speech and midface growth, including occlusion. Moreover, it incorporates results evaluated not earlier as the growth is completed.It is important, because early observations are not very reliable, since in reference to maxilla development, there is stated tendency of cephalometric measurements deterioration as long as the time flows [10].

Presentation of all and consecutive cases would be most convincing. Nevertheless, accumulation of such material after 18-20 years from primary treatment is rarely feasible. Therefore, even an incomplete and fragmentary examination of grown-up patients, might and ought to be regarded as a valuable support to long-term evaluations.

\section{Own Observations}

Between 1976 and 2008, at the University Clinic and Hospital of Plastic Surgery in Polanica Zdrój, more than 5500 cases of primary clefts were treated under the leadership of the first author (K.K.). Approximate figures result from the department and clinic transfer to the new hospital in 2004 that led to partial archive loss.

Preoperative orthodontic treatment was conducted mostly by pediatric units referring patients to surgical treatment. Systematic postoperative treatment with the use of removable and permanent devices in own outpatient clinic was introduced since 1997.

Until 1980 and then further, in about $70 \%$ of patients operated by the first author collaborators, lip repair was performed at the age of 6-8 months, most frequently with the use of triangular flap, defined as Randall's procedure. In bilateral clefts, two-stage procedure was implemented. Cleft palates repair was done approximately at the age of 2 with Veau, Wardill and Kilner methods [11-13]. Secondary lip correction and columella elongation were performed in preschool age, and alveolar bone grafts were performed between 7 and 11 years. Orthognatic operations and nose corrections requiring nasal septum resection and rhinoplasty were performed at the earliest at the age of 16 .
Patients treated in this manner were regarded as an informal control group. The same can be said about the patients primarily operated on in other units, observations of whom indirectly allowed for evaluation of various treatment protocols.

\section{New Methods}

Starting from 1980, some gradual changes of operative methods have been introduced. They aimed at reducing trauma resulting from the use of mucoperiosteal flaps and establishing safe conditions for early speech and better appearance without impairment of midface development.

\section{Unilateral clefts}

First change consisted in cleft lip repair according to Millard's technique in combination with primary nose correction according to Anderl's and Salyer's methods [14,15]. As distinct from the latter one, alar cartilages were dissected exclusively from external side only.

Since 1980, new methods in cleft palate repair consisted in the use of extended vomer flap [3,5] and reversed sequence of treatment according to Malek and Psaume [16].

In the first period of activity, the Widmaier's [17] Extended Vomer Flaps (EVF) were implemented in order to augment material on the border of the hard and soft palates [18]. Subsequently, the inferiorly pedicled vomer flaps were used for closure of all hard palates [3]. In majority of cases, simultaneous soft palate elongation with the use of mucous flaps V-Y plasty according to Perko [19] was applied (Figure 1).

In order to determine the impact of operation time on speech proficiency, palate repairs with the use of EVF were performed both at the age of 6 months, according to reversed treatment sequence, and at the age of 2 years, following cleft lip repair.

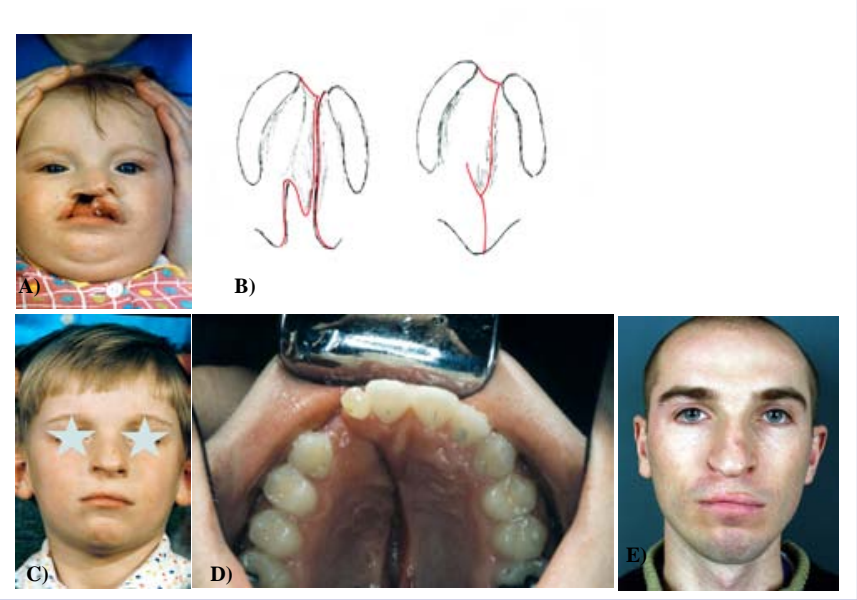

Figure 1: Unilateral cleft lip repair with Millard method followed by palate operation with vomer flap.

A - 6 months baby prior to treatment.

B - Scheme of extended vomer flap (EVF).

C - Initial patient's appearance.

D - Intraoral view after growth completion. Visible red colouration of vomer flap.

E - Patient's appearance at the age of 20 years. 
Evaluation of treatment results in unilateral clefts: Appearance, speech, midface growth and occlusion were evaluated at the earliest in 18 old patients. The appearance which did not call the attention of the society, comprehensible speech, acceptable maxillary protrusion (SNA $>75)$ as well as 3 highest degrees in dental model analysis according to GOSLON method were regarded as satisfactory outcomes [9].

Midface development: Apart from subjective general evaluation, in 2006, the outcomes of 76 UCLP patients operated on by first author between 1980 and 1998 were analyzed.

It was stated that in the random group of 53 adult patients with complete unilateral clefts treated with the use of vomer flaps, maxilla growth was better than in the group of patient's operated on according to Veau technique [5]. What is more, maxilla protrusion of these patients was favorably compared with three best European centers defined with letters A, B and E [9] (Table 1).

The most efficient procedure turned out to be the cleft lip repair performed at the age of 6 months followed by EVF palatoplasty at the age of two - group I. The facial angle in group II (palate repair with EVF at 6 months, followed by lip repair performed 2 months later) was acceptable too and amounted to 77.2 , but in this younger group, some reduction of posteriorsuperior facial height was noted.

Speech: Speech evaluation consisted on measurements of nasality and clinical examinations embracing the palate length and mobility as well as palato-pharyngeal occlusion. Articulation and speech proficiency were subjectively evaluated not only by operating team, but by the patients themselves and their parents. Nasality in the groups operated with use of EVF was considerably lesser than in the patients treated with Veau method.

Despite clinical observations indicating better speech development in the group of children operated at the age of 6 months, as long as the time passed, changes in favor of delayed operative palatoplasties performed at the age of two became evident [5]. So, contrary to anticipations, earlier operations did not contribute to better speech! Moreover the subjective speech improvement has been observed also following alveolar bone grafting and after septoplasty and rhinoplasty.

Table 1: ABE - letters identifing Eurocleft centers.

\begin{tabular}{|c|c|c|c|c|c|c|}
\hline \multicolumn{4}{|c|}{ OWN STUDY } & \multicolumn{3}{|c|}{ EUROCLEFT STUDY } \\
\hline \multicolumn{7}{|c|}{ SNA } \\
\hline 19,2 & \multirow[t]{2}{*}{ EVF } & $\begin{array}{l}\text { I group } \\
\mathrm{n}=27\end{array}$ & 77,2 & 75,7 & B & \multirow{3}{*}{17} \\
\hline 21,2 & & II group $n=26$ & 77,7 & 74,9 & $\mathrm{E}$ & \\
\hline 20 & VEAU & $\begin{array}{c}\text { III group } \\
\mathrm{n}=23\end{array}$ & 75,4 & 74,9 & A & \\
\hline AGE & \multicolumn{5}{|c|}{$\begin{array}{c}\text { GOSLON } \\
\% \text { of very good and good results }\end{array}$} & AGE \\
\hline 19,2 & \multirow[t]{2}{*}{ EVF } & $\begin{array}{l}\text { I group } \\
\mathrm{n}=27\end{array}$ & 81,0 & 86,5 & $\mathrm{E}$ & \multirow{3}{*}{17} \\
\hline 21,2 & & II group $n=26$ & 64,7 & 82,1 & A & \\
\hline 20 & VEAU & $\begin{array}{c}\text { III group } \\
\mathrm{n}=23\end{array}$ & 52,0 & 70,7 & B & \\
\hline
\end{tabular}

The management of velopharyngeal insufficiency consisted mostly in Orticochea plasty [20] and alternate Z-plasty according to Furlow's method [21]. The above procedures contributed greatly to better speech quality [22].

Patients' appearance: Apart from morphology and quality of primary operation, adult patients appearance was significantly dependant on underwent nose corrections performed at the age of 16-18 [23]. The nasal deformities resulted often from EVF method imperfection related to vomer denudation, which produced septum deviation and consequently - increased demand for rhinoplasty (Figure 2).

Orthognathic operations undisputably improved adult patients' appearance too. From among 76 adult subjects, Goslon 5 degree requiring integrated orthodontic and surgical treatment was observed in six subjects, four of them operated with Veau technique. High osteotomy of Le Fort I type was performed in 5 patients and distraction method was applied in one subject.

\section{Bilateral clefts}

Implemented changes consisted in two-stage lip operation with modified Millard's method, early columella elongation and less frequent than in unilateral clefts, use of vomer flaps.

Principle of two-stage operation was maintained in order to avoid extensive tension produced by simultaneous bilateral suturing of orbicularis oris (Figure 3).

Despite own research conducted in 134 patients with bilateral clefts which suggested better lip eversion and protrusion of vermilion in patients operated according to Randall's method, operations carried out with modified Millard's method proved more advantageous [24].

Additional benefits of two-stage lip repair consisted in temporary shallowing of buccal vestibule and enhancement of delicate, pressure of the orbicularis oris, facilitating orthodontic treatment. Premaxilla luxations occurred very rarely, yet if they emerged, an orthodontic correction was relatively easy.

Early columella elongation according to own method was introduced in 1982 aiming at reduction operative stages and avoidance of scar reoperations following primary lip repair. Until 1987, 52 patients were successively operated [25]. Delayed observations allowed for conclusion that results were and still remain permanent without necessity of reoperations (Figure 4).

Nevertheless, due to complexity of operative procedure and extensive dissection of prolabium during the second stage of lip repair, in majority of cases conventional forked flap plasty was gradually restored (Figure 5).

Palate repair: In bilateral clefts, palate operations with vomer flaps were performed less frequently than in unilateral clefts. In patients with minor protrusion of premaxilla, one-side lip repair combined with veloplasty and one-side hard palate repair was followed by final second side lip and hard palate closure performed 2 months later (Figure 6).

In patients with significant premaxillary protrusion, primary 


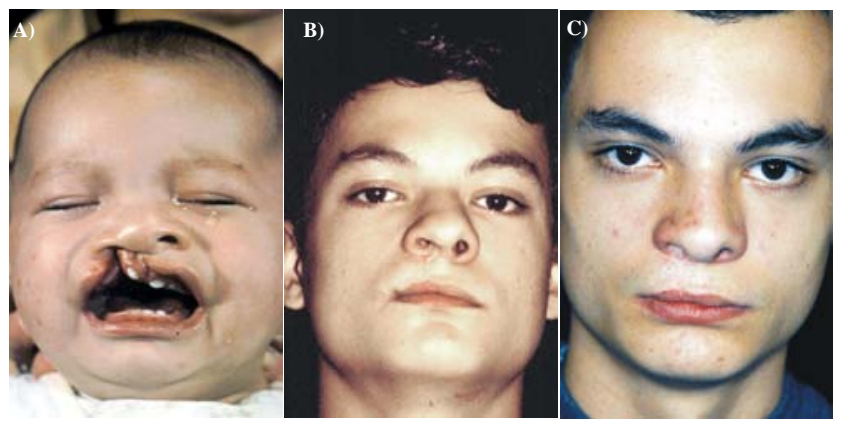

Figure 2: A - 6 months baby prior to operation. B - Patient 16 years old. Visible septum deviation.

C-Patient's appearance rhinoplasty. Long-term outcome.
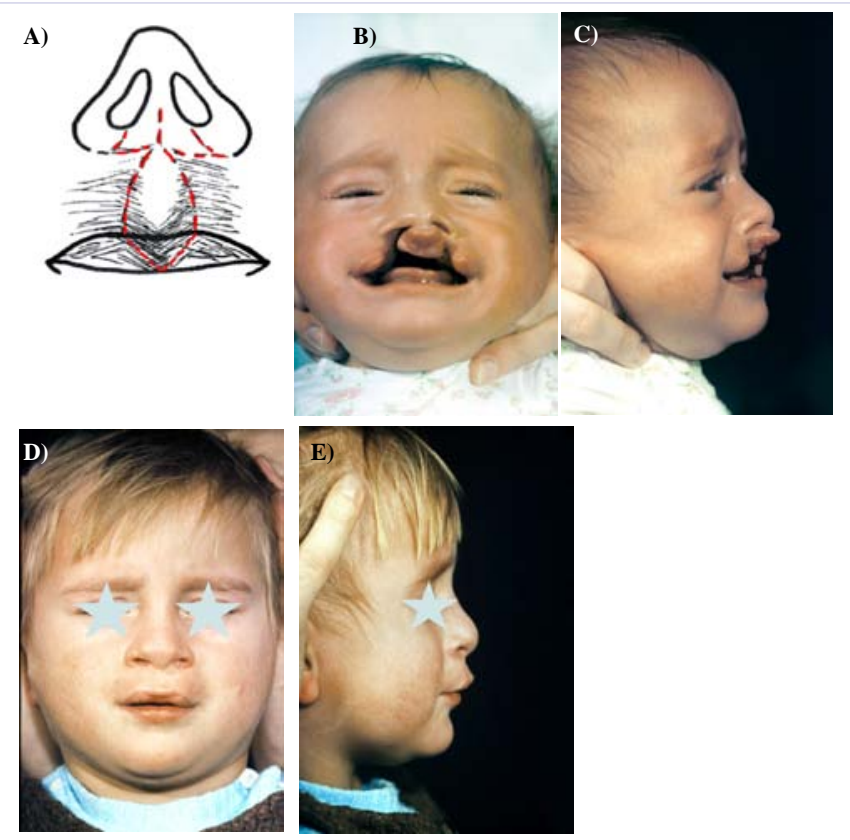

Figure 3: A - Scheme of muscle anastomosis and example of two-stage bilateral cleft lip repair preoperatively (B, C) and postoperatively (D, E)
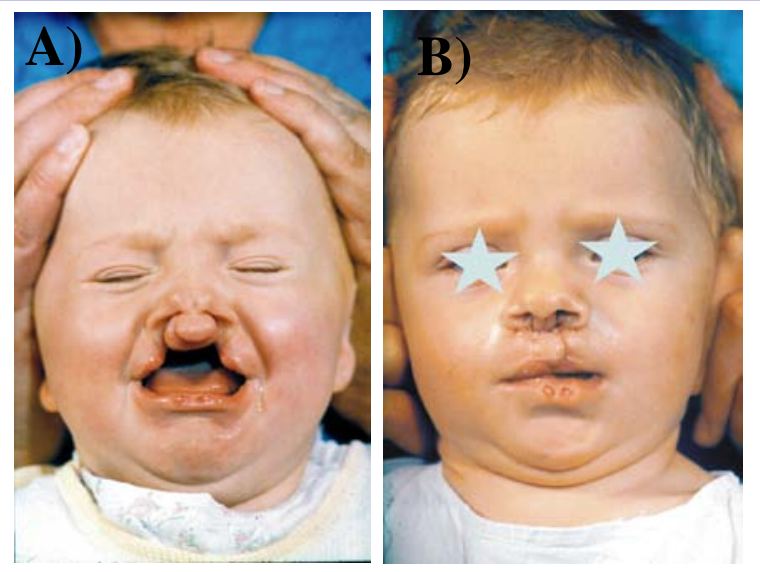

Figure 4: A - 6 months baby preoperatively.

B - Child's appearance immediately after lip repair and columella elongation.

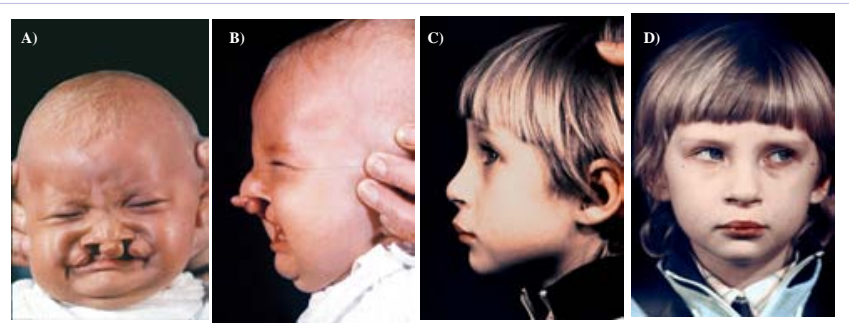

Figure 5: Delayed columella elongation. A, B - Preoperatively. C, D - Patient's appearance after columella elongation in preschool age.

operation consisted in veloplasty, whereas hard palate repair was postponed until completion of orthodontic treatment (Figure 7).

Evaluation of treatment results in bilateral clefts: Due to heterogeneity of clinical material and significantly fewer adult patients registering to control examinations, conduction of evidence-based research was considered futile.

Subjectively however, both appearance and speech of patients operated with new methods seemed to be better (Figure 8).

Midface growth and occlusion of patients treated with mucoperiosteal flap transposition (Veau method) appeared to be less satisfactory in comparison to those operated with use of vomer flaps (EVF).

\section{Discussion}

Basic principles of CLP repair are commonly known, yet operative methods; sequence and timing of operations are still open for discussion [26,27]. Existing differences and various protocols are self-evident, because every method has some shortcomings eliminating their general approval.

The new methods are probably most efficient in the hands of their authors. The attempts of imitation are connected with socalled learning curve and happen to end up with disappointment and discouragement. Consequently, there is a tendency to traditional old patterns in spite of awareness of their drawbacks and shortcomings.

On the other side, cleft treatment calls for improvements and the question is what and how it should be accomplished. Unfortunately, chances for essential improvements are rather vague and the range of treatment alternatives is rather limited.

The basic problem is the tissue deficiency and its quality. Such point of view is not new, since cleft morphology is the main factor determining treatment results [26]. Yet, in practical application, it turns out to be a void approach since irrespective of cleft severity, majority of methods relies on transposition of deficient and hypoplastic tissues.

Well known from literature and described above "borrowing" of vomer tissue (EVF) is not ideal, because healing of donor side through granulation causes nasal septum deformations. Other sources of tissues are very limited. Buccal flaps are of a little size and their transfer entails extensive dissection [28]. The tongue flaps are solely used in corrective operations [29] and promising 
attempts to apply them in primary operations (K.K.) are not continued, alas.

Solution to this problem was to get tissue expansion by means of osmotic expanders [30,31] in order to increase the amount of material and facilitate palate repair without necessity of mucoperiosteal flaps transposition and harmful release incisions. Despite encouraging outcomes, in our hands, the method proved to be effective only in relatively narrow clefts, up to $12 \mathrm{~mm}$. In wider clefts, especially those exceeding $15 \mathrm{~mm}$, quite often-

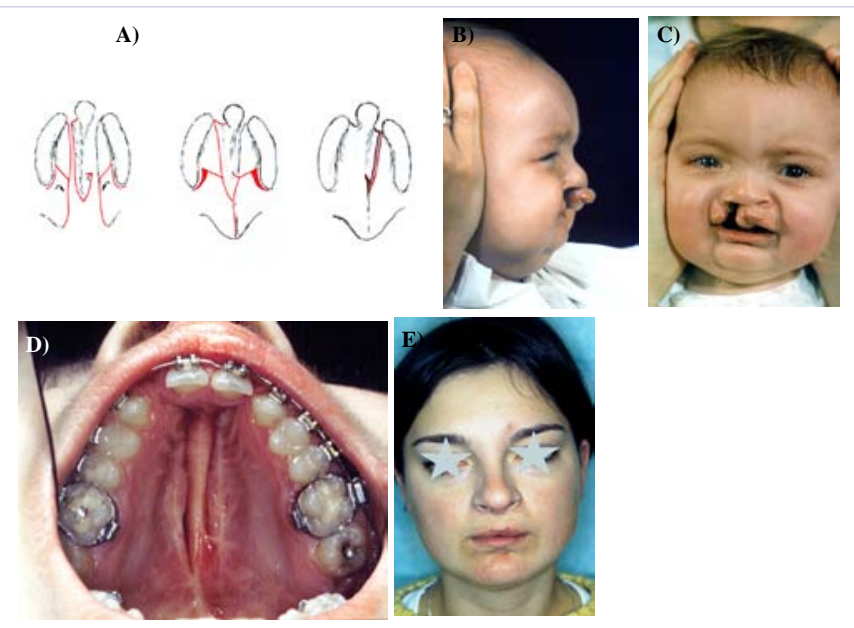

Figure 6: BCLP with moderate protrusion of premaxilla.

A - Schematic representation of staged palate repair with the use of $\mathrm{EVF}$ and $\mathrm{V}-\mathrm{Y}$ mucosal flap plasty.

B, C - 6 months old patient after veloplasty and one-side lip and hard palate repair.

D - Long-term result of palate repair and -

E - Final patient appearance.

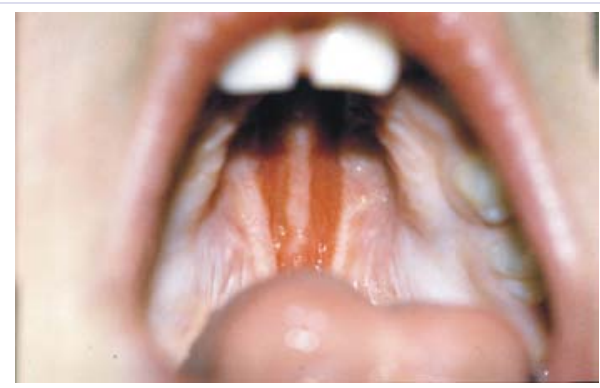

Figure 7: Example of bilateral cleft palate repair (see text)

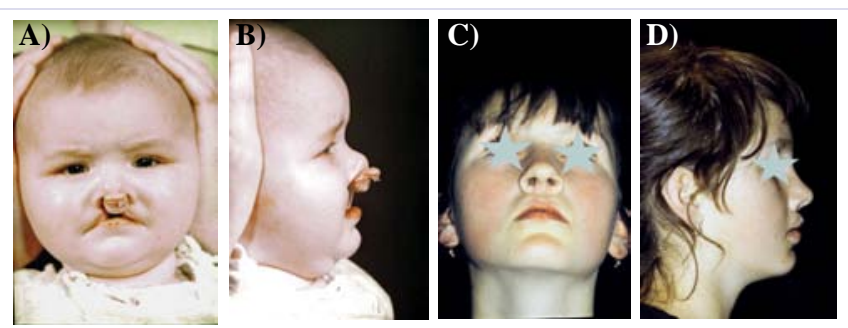

Figure 8: A, B-Child 6 months old before treatment. C, D- Final outcome, after primary repair only.
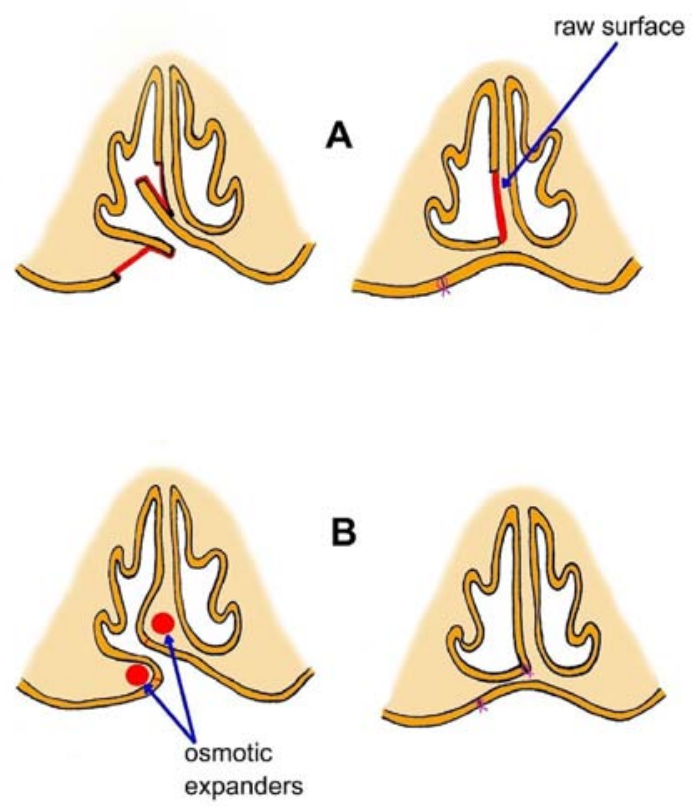

B

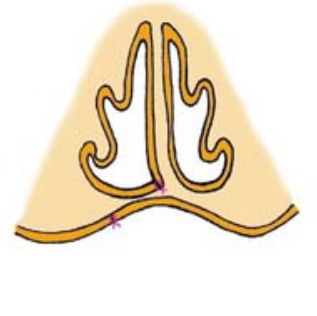

Figure 9: A - Schematic representation of vomer flap application. In red marked the wounds healing through granulation.

B - Scheme of operation mentioned above preceded by osmotic expanders implantation. Tissue expansion enabling closure of secondary defect after vomer flap elevation.

residual palatal fistulae were noted.

Apart from hard palate mucosa and periosteum augmentation, expanders were used also to expand vomer mucosa, so that secondary defects following EVF plasty might be healed per primam intentionem. The preliminary efforts aimed at merge and improvement of the above mentioned EVF plasty are promising indeed, however evaluation of this technique, based on 50 cases only and less than 10 years observations is rather premature. Nevertheless, judging from initial observations [30] and experimental data [31], an augmentation of tissues with the use of expanders seems to be effective and logical (Figure 9).

So far, significant disadvantage in application of osmotic expanders is the lack of control and too rapid expansion lasting 24-48 hours only. Consequently, the use of expanders demands some experience and precaution, because too big implants might end up with disruption of tissues. As a hope to answer this problem is the use of miniaturized expanders composed of containers with compressed carbon dioxide, gradual release of which might be remote controlled [32]. Will it be realistic and useful? Who knows, but even if it sounds as a science fiction, the idea of tissue augmentation deserves more attention.

\section{Conclusion}

Although an ideal management of clefts is unrealistic, the use of relatively harmless and sparing metods enables achievement of satisfactory speech, appearance and midface development. In UCLP patients treated with the use of extended vomer flaps, maxilla protrusion were favorably compared with three the best 
European centers [9], and their speech was better in comparison with the group of patients operated on according to Veau technique [5]. An evaluation was performed at the earliest in 18 year old patients, so it should be regarded as a final outcomes.

As the patients appearance depends on numerous factors, such as primary or delayed nose repair, alveolar bone grafts or secondary lip and nose corrections [23-25] no precise measurements were taken, but according to subjective evaluation the outcomes were regarded as satisfactory.

Despite reasonably good outcomes, the prospect for essential improvement in complete cleft repair sems to be rather vague and determined mostly by tissue deficiency. Judging from literature and own observations, no more should be expected from various palate or vomer flap transpositions, because there is a deficit of reconstructive material.

Therefore an idea of tissue augmentation is logical and reasonable, the more so as our early outcomes of palate repair with the use of osmotic expanders [30] are promising indeed and supported by experimental data [31]. Although 10 year observations and clinical material of 50 patients is not enough and premature for final conclusions, the new approach deserves more attention and hopefully, invention of more sophisticated expanders.

\section{References}

1. Schweckendiek H. Zur Frage der Fruh-und Stat-operation der angeborenen Lippen-Kiefer-Gaumenspalten. Zeitschrift fur Laryngologie. 1951; 30: 51-56.

2. Perko M. Two-stage palatoplasty. In: Bardach J, Morris HL, editors Multidisciplinary Management of Cleft Lip and Palate. New York; WB Saunders Co.1990; 311-22.

3. Kobus K. Extended vomer flap in the early repair of a cleft palate. Scand J Plast Reconstr Surg Hand Surg. 1987; 21(1):95-102.

4. Rohrich RJ, Roswell AR, Johns DF, Drury MA, Grieg J, Watson DJ, et al. Timing of hard palate closure: a critical long-term analysis. Plast Reconstr Surg. 1996; 98(2):236-46.

5. Kobus K, Pisulska-Otremba A, Wójcicki P, Wójcicka G, Kobus-Zaleśna K. Long-term results of palatoplasty with extended vomer flaps versus Veau method. One surgeon's experience. Polski Przegląd Chirurgiczny. 2006; 78(11):1261-76.

6. Desai SN. Cleft lip repair in newborn babies. Ann R Coll Surg Engl. 1990; 72(2):101-3.

7. De Mey A, Franck D, Cyulits N, Swennen G, Malevez C, Lejour M. Early one-stage repair of complete unilateral cleft lip and palate. J Craniofac Surg. 2009; 20:1723-8. doi: 10.1097/SCS.0b013e3181b3ef71.

8. Ross RB. Treatment variables affecting facial growth in complete unilateral cleft lip and palate. Cleft Palate J. 1987; 24(1):5-77.

9. Molsted K, Brattstrom V, Prahl-Andersen G, Shaw WC, Semb G. The Eurocleft study: intercenter study of treatment outcome in patients with complete cleft lip and palate. Part 3. dental arch relationships. Cleft Palate Craniofac J. 2005; 42(1):78-82.

10. Semb G. A study of facial growth in patients with unilateral cleft lip and palate treated by the Oslo CLP Team. Cleft Palate Craniofac J. 1991; 28(1):1-21.
11. Veau V, Borel S. Division Palatine. Masson; Paris 1931.

12. Wardill WEM. Cleft palate. British Journal of Surgery. 1928; 16:121.

13. Kilner TP. Cleft lip and palate repair technique. St Thomas Hospital Rep 1937;2:127

14. Anderl H, Hussl H, Ninkovic M. Primary simultaneous lip and nose repair in the unilateral cleft lip and palate. Plast Reconstr Surg. 2008; 121(3):959-70. doi: 10.1097/01.prs.0000299942.84302.16.

15. Salyer KE, Genecov ER, Genecov DG. Unilateral cleft lip-nose repair long term outcome. Clin Plast Surg. 2004; 31(2):191-208.

16. Malek R, Psaume J. Nouvelle conception de la chronologie de la technique chirurgicale du traitement des fentes labio-palatines. Annales de Chirurgie Plastique et Esthetique. 1983; 28:237-247.

17. Widmaier W. Eineigenes VerfahrenzumVerschluss der Gaumenspalte. Der Chirurg 1959; 30:274.

18. Kobus K. Extended vomer flaps in cleft palate repair: a preliminary report. Plast Reconstr Surg. 1984; 73(6):895-903.

19. Perko MA. Primary closure of the cleft palate using a palatal mucosal flap; an attempt to prevent growth impairment. J Maxillofac Surg. 1974; 2(1):40-3.

20. Orticochea, M. A review of 236 cleft patients treated with dynamic muscle sphincter. Plast Reconstr Surg. 1983; 71(2):180-8.

21. Furlow LT Jr. Cleft palate repair by double opposing Z-plasty. Plast Reconstr Surg. 1986; 78(6):724-38.

22.Wójcicki P, Świdziński P, Wójcicka G. Velopharyngeal incompetence treated by the pharyngeal flap and the Orticochea pharyhgoplasty- a comparison of speech results. Otolaryngol Pol. 2005; 59(5):705-12.

23. Kobus K. Cleft lip nose surgery. Scand J Plast Reconstr Surg Hand Surg. 1987; 21(1):87-94.

24. Kobus K, Martinek J. Two-staged repair of 134 bilateral clefts by the same surgeon: a comparison of the triangular and modified rotationadvancement methods. In: Pfeifer (Ed): Craniofacial Abnormalities and Clefts of the Lip, Alveolus and Palate. New York. Thieme. 1991; 317-20.

25. Kobus K. Early columella elongation. Ann Plast Surg. 1987; 18(6):4709.

26. Shaw WC, Dadl E, Asher-McDade C, Brattstrom V, Mars M, McWilliam $\mathrm{J}$, et al. A six-center international study of treatment outcome in patients with clefts of the lip and palate: Part 5. General discussion and conclusion. Cleft Palate Craniofac J. 1992; 29(5):413-8.

27. Kobus K, Kobus-Zaleśna K. Timing of cleft lip and palate repair. Dev Period Med. 2014; 18(1):78-83.

28. Bozola AR, Gasques JA, Carriquiry CE, Cardoso de Oliveira M. The buccinator musculomucosal flap; anatomic study and clinical application. Plast Reconstr Surg. 1989, 84(2):250-7.

29. Kobus K, Łątkowski I. The treatment of palatal defects with the use of tongue flaps. Czas Stomatologiczny. 2002; 55:720-7.

30. Kobus KF. Cleft palate repair with the use of osmotic expanders: a preliminary report. J Plast Reconstr Aesthet Surg. 2007; 60(4):414-21.

31.Wysocki M, Kobus K, Szotek S, Kobielarz M, Kuropka P, Będziński R. Biomechanical effect of rapid musculoperiosteal palatal tissue expansion with the use of osmotic expanders. J Biomech. 2011; 44(7):1313-20. doi: 10.1016/j.jbiomech.2011.01.012.

32.Zeidler K, Laurence Berkowitz R, Johnson D, Castle J, Morris D, Chun 
Y, et al. Patient activated controlled tissue expander system for breast reconstruction; A prospective, multicenter, randomized, controlled, open label clinical study-preliminary results. AAPS 93-rd Annual Meeting Abstract. Miami, April 5-8, 2014. 